\title{
Solvothermal Synthesis and Photocatalytic Properties of Nitrogen-Doped $\mathrm{SrTiO}_{3}$ Nanoparticles
}

\author{
Uyi Sulaeman, Shu Yin, and Tsugio Sato \\ Institute of Multidisciplinary Research for Advanced Materials, Tohoku University, 2-1-1, Katahira, Aoba-ku, Sendai 980-8577, Japan \\ Correspondence should be addressed to Tsugio Sato, tsusato@tagen.tohoku.ac.jp \\ Received 13 April 2010; Accepted 6 August 2010 \\ Academic Editor: Justin D. Holmes \\ Copyright () 2010 Uyi Sulaeman et al. This is an open access article distributed under the Creative Commons Attribution License, \\ which permits unrestricted use, distribution, and reproduction in any medium, provided the original work is properly cited. \\ Perovskite-type nitrogen-doped $\mathrm{SrTiO}_{3}$ nanoparticles of $50-80 \mathrm{~nm}$ in diameter were successfully synthesized by the solvothermal \\ of $\mathrm{Ti}\left(\mathrm{OC}_{3} \mathrm{H}_{7}\right)_{4}, \mathrm{SrCl}_{2} \cdot 6 \mathrm{H}_{2} \mathrm{O}$, and hexamethylenetetramine in $\mathrm{KOH}$ aqueous solution. Nitrogen-doped $\mathrm{SrTiO}_{3}$ showed excellent \\ photocatalytic activity under both UV and visible light irradiation, that is, the photocatalytic activity of $\mathrm{N}$-doped $\mathrm{SrTiO}_{3}$ for \\ $\mathrm{DeNO}_{x}$ reaction was greater than that of $\mathrm{SrTiO}_{3}$ and commercial $\mathrm{TiO}_{2}$ (Degussa P25) in both visible light region $(>510 \mathrm{~nm})$ and \\ UV light region $(>290 \mathrm{~nm}$ ). The excellent visible light photocatalytic activity of this substance was caused by generating a new \\ band gap that absorbs visible light.
}

\section{Introduction}

Strontium titanate is one of the excellent photocatalysts that could be used in water splitting for hydrogen energy production and degradation of organic contaminant under ultraviolet irradiation. Unfortunately, the photocatalytic activity is not high application in visible light because of relatively large band gap energy of $3.2 \mathrm{eV}$. Therefore, to extend the absorption range of strontium titanate towards the visible range is essential work to generate visible light responsive photocatalyst. It is a great challenge to synthesize the catalyst which is active under visible light irradiation to use sun light. The research of photocatalyst in the field of visible light region has attracted many researchers [15]. Doping with metal or nonmetal ion to $\mathrm{SrTiO}_{3}$ material could extend its optical absorption edge towards the visible light range and generate the photocatalytic activity in visible light. Many studies have focused on nitrogen doping due to well-responsive photocatalytic activity in visible light. It is well known that the substituting of oxygen ion by nitrogen ion can generate the new band gap of photocatalyst [6]. The photocatalytic activity of the catalysts may depend on the preparation method due to the difference in the specific surface area, particle size, and crystallinity of the catalyst. Nitrogen-doped $\mathrm{SrTiO}_{3}$ could be prepared by the mechanochemical reaction of $\mathrm{SrTiO}_{3}[6-8]$ using doping sources such as hexamethylenetetramine, urea, ammonium carbonate, and thiourea, and using a high energy planetary ball mill and agate mortar. However, the mechanochemical reaction tends to generate stress on the surface of the product and leads to depressing the photocatalytic activity. Therefore, we synthesized the $\mathrm{N}$-doped $\mathrm{SrTiO}_{3}$ nanoparticles using solvothermal reaction in $\mathrm{KOH}$ aqueous solution to obtain the fine particles and high specific surface area. The visible responsive photocatalyst could be enhanced by this method.

\section{Experimental}

2.1. Preparation. Titanium tetraisopropoxide $\mathrm{Ti}\left(\mathrm{OC}_{3} \mathrm{H}_{7}\right)_{4}$ and $\mathrm{SrCl}_{2} \cdot 6 \mathrm{H}_{2} \mathrm{O}$ were used as starting materials, hexamethylenetetramine (HMT) as a source of nitrogen, and $\mathrm{KOH}$ as a mineralizer. All of them were reagent grade and used without further purification. After dissolving titanium tetraisopropoxide, $\mathrm{Ti}\left(\mathrm{OC}_{3} \mathrm{H}_{7}\right)_{4}$ in $10 \mathrm{~mL}$ 2-propanol, $\mathrm{SrCl}_{2}$ aqueous solution was added dropwise to $\operatorname{Ti}\left(\mathrm{OC}_{3} \mathrm{H}_{7}\right)_{4} 2-$ propanol solution with stirring continuously, and then 0 6 gram of HMT and $20 \mathrm{~mL}$ of $2 \mathrm{M} \mathrm{KOH}$ aqueous solution were added in turn. The mixed solution was placed into a stainless steel autoclave inserted with a Teflon container. After that, the autoclave was heated at $200^{\circ} \mathrm{C}$ for 3 hours. After cooling the autoclave to room temperature, the powder 


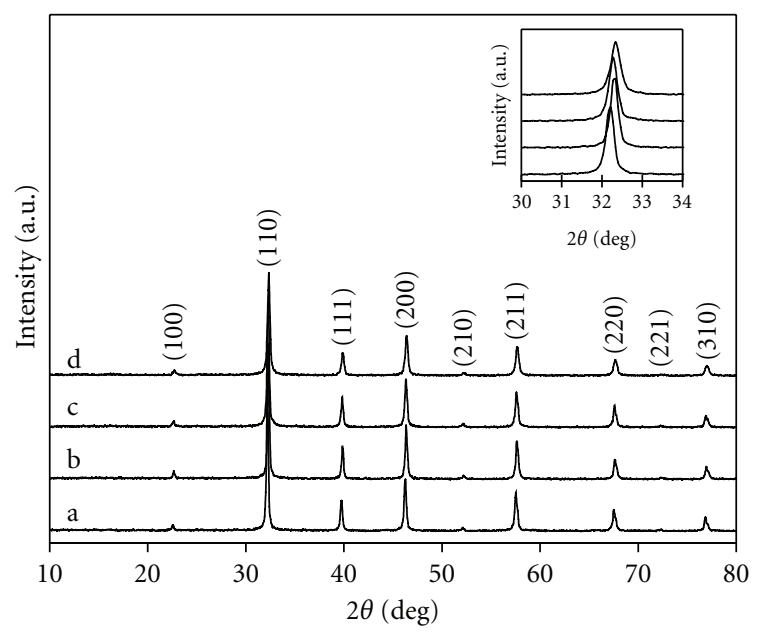

FIGURE 1: XRD patterns of sample prepared by solvothermal method, $\mathrm{SrTiO}_{3}$ (a), N-doped $\mathrm{SrTiO}_{3}$ with HMT of 1 gram (b), 2 gram (c), and 4 gram (d). The insert indicates the (110) peak shift due to nitrogen doping.

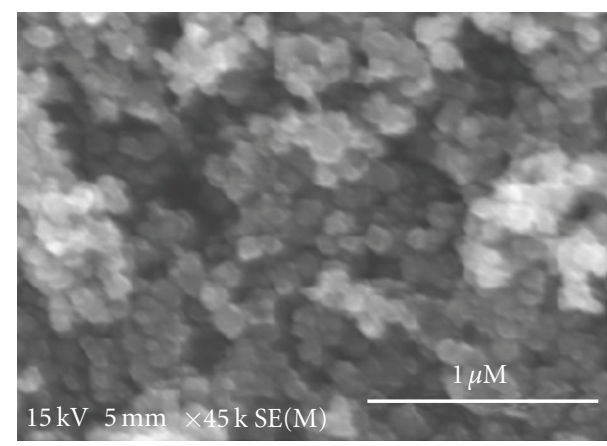

(a)

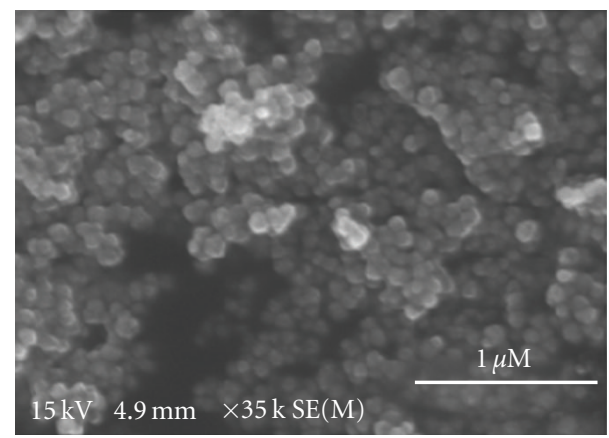

(b)

Figure 2: SEM images of $\mathrm{SrTiO}_{3}$ (a) and N-doped $\mathrm{SrTiO}_{3}$ synthesized by solvothermal reaction with 4 gram of HMT (b).

product was separated by centrifugation, washed with distilled water and acetone three times, respectively, then dried in vacuum at $60^{\circ} \mathrm{C}$ overnight.

2.2. Characterization. The powder product was characterized by X-ray diffraction analysis (XRD, Shimadzu $\mathrm{XD}-\mathrm{D} 1)$ using graphite-monochromized $\mathrm{CuK} \alpha$ radiation.

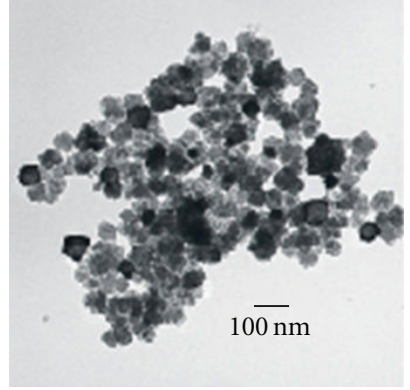

(a)

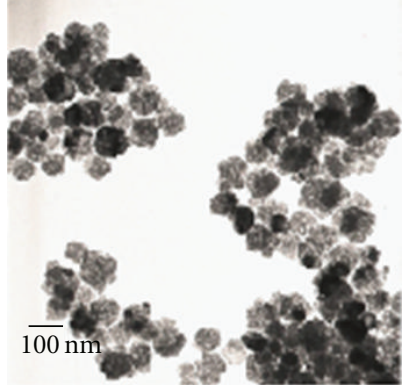

(b)
Figure 3: TEM images of $\mathrm{SrTiO}_{3}$ (a) and N-doped $\mathrm{SrTiO}_{3}$ synthesized by solvothermal reaction with 4 gram of HMT (b).

Microstructures were observed by scanning electron microscope (FE-SEM, Hitachi, S-4800) and transmission electron micrograph (TEM, JEOL JEM-2010). The specific surface areas were determined by the nitrogen adsorption at $77 \mathrm{~K}$ (BET, Quantachrome NOVA 4200 e). The vibration spectra were characterized by FTIR (FTS 7000 series, DIGILIB). The UV-vis diffuse reflectance spectra were measured at room temperature with a UV-vis spectrophotometer (Shimadzu UV-2450) in the range $250-800 \mathrm{~nm}$. Binding energies of the samples were analyzed at room temperature by X-ray photoelectron spectroscopy (Perkin-Elmer PHI 5600).

2.3. Photocatalytic Activity Evaluation. The photocatalytic activity for the $\mathrm{NO}_{x}$ destruction was determined by measuring the concentration of $\mathrm{NO}_{x}$ gas at the outlet of the reactor during the photoirradiation of a constant flow of a mixed gas containing $1 \mathrm{ppm} \mathrm{NO}_{x}-50$ vol.\% air (balance $\mathrm{N}_{2}$ ). The photocatalyst sample was placed in a hollow of $20 \mathrm{~mm}$ length $\times 15 \mathrm{~mm}$ width $\times 0.5 \mathrm{~mm}$ depth on a glass holder plate and set in the bottom centre of the reactor. A $450 \mathrm{~W}$ high-pressure mercury arc was used as the light source. The wavelength of the irradiation light was controlled by selecting filters, that is, Pyrex glass for $\lambda>290 \mathrm{~nm}$, Kenko L41 Super Pro (W) filter for $\lambda>400 \mathrm{~nm}$, and Fuji, tri-acetyl cellulose filter for $\lambda>$ $510 \mathrm{~nm}$. The concentration of $\mathrm{NO}_{x}$ was determined using an $\mathrm{NO}_{x}$ analyzer (Yanaco, ECL-88A).

\section{Results and Discussion}

3.1. Solvothermal Synthesis of N-Doped $\mathrm{SrTiO}_{3}$. Nitrogendoped $\mathrm{SrTiO}_{3}$ was successfully synthesized by solvothermal reaction in $\mathrm{KOH}$ aqueous solution using tetraisopropoxide, $\mathrm{Ti}\left(\mathrm{OC}_{3} \mathrm{H}_{7}\right)_{4}$, and $\mathrm{SrCl}_{2} \cdot 6 \mathrm{H}_{2} \mathrm{O}$ as the starting material and hexamethylenetetramine (HMT) as nitrogen source. It is well known that HMT could be degraded into ammonia and formaldehyde by heating in water above $70^{\circ} \mathrm{C}$ [9]. The ammonia is the key factor of nitrogen doping in catalyst synthesis. By the solvothermal reaction synthesis, ammonia could react with the starting material to produce the catalyst from bottom up. The ammonia decomposed from HMT was absorbed on the surface of developing and growing strontium titanate nanocrystal and reacted with activated 


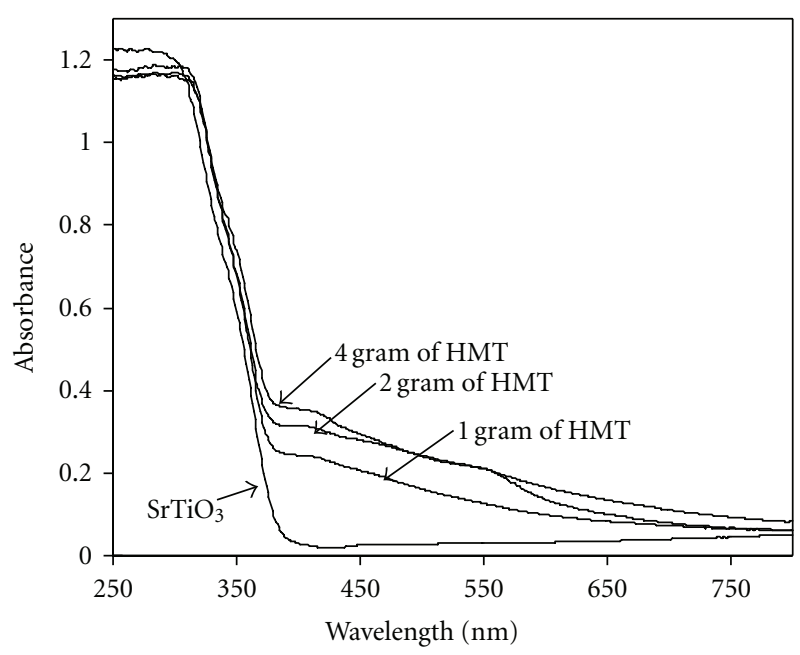

(a)

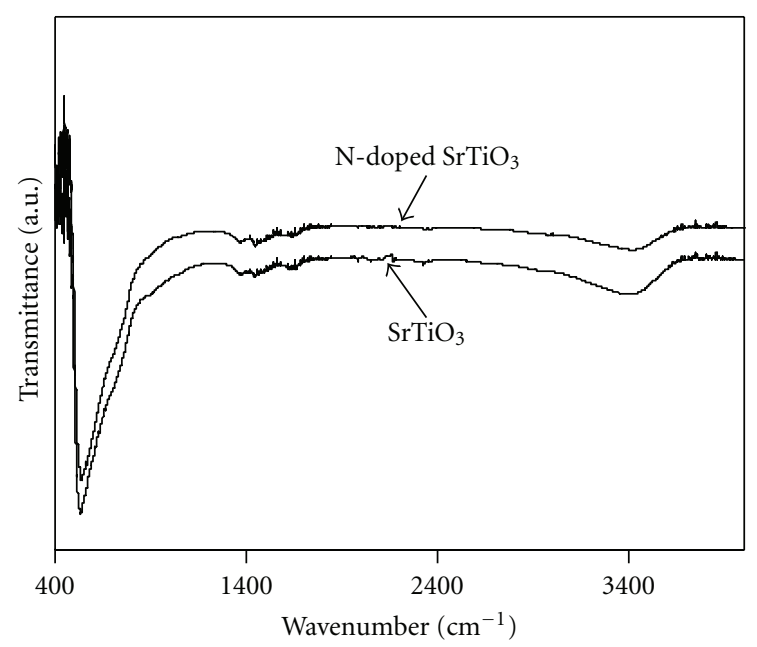

(b)

Figure 4: UV-vis DRS of $\mathrm{SrTiO}_{3}$ and $\mathrm{N}$-doped $\mathrm{SrTiO}_{3}$ synthesized by solvothermal method with 1-4 gram of HMT (a) and FTIR spectra of $\mathrm{SrTiO}_{3}$ and $\mathrm{N}$-doped $\mathrm{SrTiO}_{3}$ with 4 gram of $\mathrm{HMT}$ (b).

strontia-titania surface, then generating the nitrogen doping in the solvothermal reaction. The yellow crystalline of $\mathrm{N}$ doped $\mathrm{SrTiO}_{3}$ could be obtained. The reaction for the synthesis of $\mathrm{N}$-doped $\mathrm{SrTiO}_{3}$ (1) can be described as

$$
\begin{aligned}
\mathrm{Ti}\left(\mathrm{OC}_{3} \mathrm{H}_{7}\right)_{4}+2 \mathrm{H}_{2} \mathrm{O} & \longrightarrow \mathrm{TiO}_{2}+4 \mathrm{C}_{3} \mathrm{H}_{7} \mathrm{OH} \\
\mathrm{SrCl}_{2} \cdot 6 \mathrm{H}_{2} \mathrm{O}+2 \mathrm{KOH} & \longrightarrow \mathrm{Sr}(\mathrm{OH})_{2}+2 \mathrm{KCl}+6 \mathrm{H}_{2} \mathrm{O} \\
\mathrm{Sr}(\mathrm{OH})_{2}+\mathrm{TiO}_{2} & \longrightarrow \mathrm{SrTiO}_{3}+\mathrm{H}_{2} \mathrm{O} \\
\mathrm{C}_{6} \mathrm{H}_{12} \mathrm{~N}_{4}+6 \mathrm{H}_{2} \mathrm{O} & \longrightarrow 6 \mathrm{HCHO}+4 \mathrm{NH}_{3} \\
\mathrm{SrTiO}_{3}+\mathrm{yNH}_{3} & \longrightarrow \mathrm{SrTiO}_{3-3 \mathrm{y} / 2} \mathrm{~N}_{\mathrm{y} \square \mathrm{y} / 2}+3 \frac{\mathrm{y}}{2} \mathrm{H}_{2} \mathrm{O}
\end{aligned}
$$

( $\square$ : lattice defect).
TABLE 1: Crystallite size and surface area of $\mathrm{SrTiO}_{3}$ and N-doped $\mathrm{SrTiO}_{3}$.

\begin{tabular}{lcc}
\hline Photocatalyst & $\begin{array}{c}\text { Crystal size } \\
(\mathrm{nm})\end{array}$ & $\begin{array}{c}\text { Specific } \\
\text { surface area } \\
\left(\mathrm{m}^{2} / \mathrm{g}\right)\end{array}$ \\
\hline $\mathrm{SrTiO}_{3}$ & 40 & 29.5 \\
1 gram of HMT & 43 & 20.5 \\
2 gram of HMT & 38 & 28.5 \\
4 gram of HMT & 35 & 27.9 \\
4 gram of HMT calcined at $200^{\circ} \mathrm{C}$ & 34 & 25.8 \\
4 gram of HMT calcined at $300^{\circ} \mathrm{C}$ & 35 & 29.6 \\
4 gram of HMT calcined at $400^{\circ} \mathrm{C}$ & 48 & 31.7 \\
\hline
\end{tabular}

3.2. XRD Characterization. Figure 1 shows the XRD pattern of undoped and $\mathrm{N}$-doped $\mathrm{SrTiO}_{3}$ by solvothermal reactions at $200^{\circ} \mathrm{C}$ for 3 hours with variation of HMT content. All diffraction peaks could be assigned to the perovskite-type structure of $\mathrm{SrTiO}_{3}$ with cubic symmetry (JCPDS no. 790176). The diffraction peak position for N-doped $\mathrm{SrTiO}_{3}$ shifted to higher angle as shown in the insert of Figure 1. It indicated that the lattice constant decreased with nitrogen doping. Since the radius of $\mathrm{O}^{2-}(1.40 \AA)$ is smaller than $\mathrm{N}^{3-}(1.71 \AA)$, the decrease of lattice constant of $\mathrm{SrTiO}_{3}$ with nitrogen doping may be due to the formation of anion vacancy for charge compensation as $\mathrm{SrTiO}_{3-3 y / 2} \mathrm{~N}_{\mathrm{y} \square \mathrm{y} / 2}(\square$ : lattice defect).

The average crystallite sizes calculated by Scherrer's Equation (2) using the full width at half maximum (FWHM) of the most intense peak (110) are also listed in Table 1 together with the specific surface areas

$$
D=\frac{0.9 \lambda}{B \cos \theta}
$$

where $D$ is the average crystallite size or particle size, $\lambda$ the $\mathrm{X}$-ray wavelength $(0.15418 \mathrm{~nm}), \theta$ the Bragg angle, and $B$ the FWHM. The samples consisted of nanoparticles of $35-48 \mathrm{~nm}$ in diameter and specific surface area of $20.5-31.7 \mathrm{~m}^{2} \mathrm{~g}^{-1}$ and did not change so much with nitrogen doping and following calcination.

3.3. Morphology. The images of SEM of $\mathrm{SrTiO}_{3}$ and nitrogen-doped $\mathrm{SrTiO}_{3}$ are shown in Figure 2. The sample consisted of sphere particles with the particles size around $50-80 \mathrm{~nm}$, which is slightly larger than those calculated by Scherrer's equation (see Table 1). The particle size is uniform, and no agglomeration could be observed (Figure 3). Table 1 shows that the specific surface area of catalyst is not well correlated with the crystal size. Usually, the smaller the particle size, the higher the specific surface area. In this case, because of the organic compound adsorbed on the surface, the irregular correlation between the surface area and particle size was obtained.

3.4. DRS and FTIR. The UV-Vis absorption spectra of $\mathrm{SrTiO}_{3}$ and $\mathrm{N}$-doped $\mathrm{SrTiO}_{3}$ determined by diffuse reflectance analysis are shown in Figure 4(a). $\mathrm{SrTiO}_{3}$ showed 


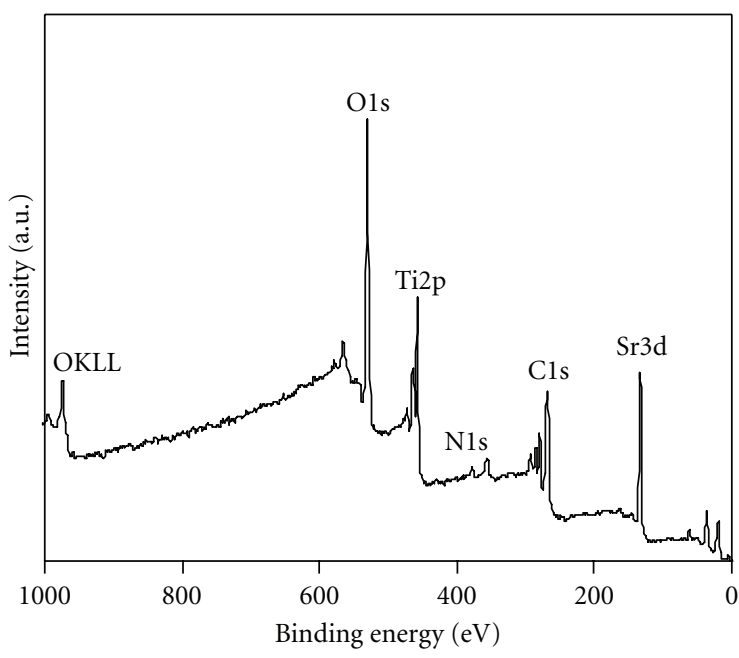

(a)

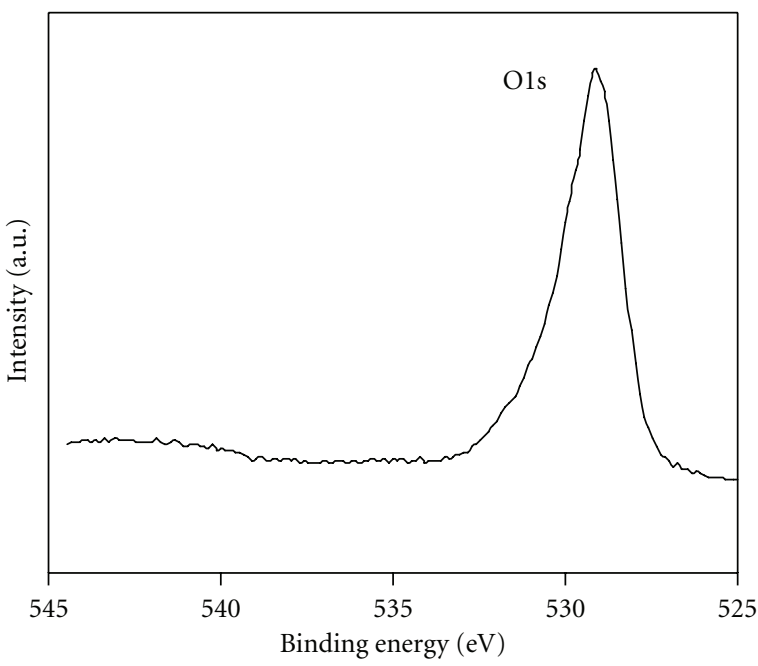

(c)

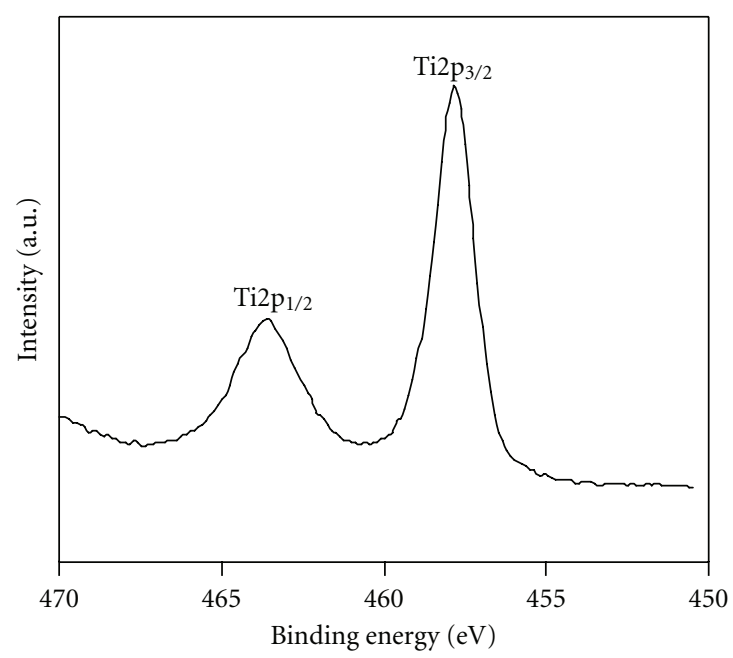

(b)

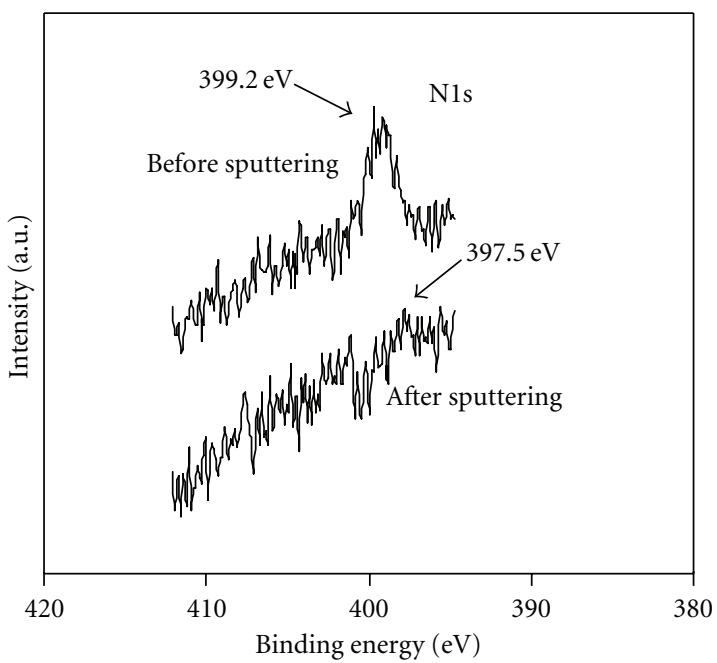

(d)

Figure 5: XPS spectra of $\mathrm{N}$-doped $\mathrm{SrTiO}_{3}$ synthesized by solvothermal method with 2 gram of $\mathrm{HMT}$, calcined at $200^{\circ} \mathrm{C}$ in air: (a) global spectrum; (b) Ti2p; (c) O1s; (d) N1s, Ar ${ }^{+}$sputtering was carried out at $3 \mathrm{kV}$ for 3 minutes.

an absorption edge at $386 \mathrm{~nm}$ corresponding to the band gap energy $3.21 \mathrm{eV}$. On the other hand, $\mathrm{N}$-doped $\mathrm{SrTiO}_{3}$ showed new absorption edges, around $400-550 \mathrm{~nm}$. The absorption edges at $400-550 \mathrm{~nm}$ may be corresponding to the nitrogendoped $\mathrm{SrTiO}_{3}$ as the electric transition from N2p to Ti3d. The absorption spectra at visible region were increased by increasing of HMT content in the reaction. The absorption spectra are also broad in the higher of wavelength more then $550 \mathrm{~nm}$. It presumed that the absorption above $550 \mathrm{~nm}$ is due to oxygen vacancy. The replacing of $\mathrm{O}^{2-}$ with $\mathrm{N}^{3-}$ in $\mathrm{N}$-doped $\mathrm{SrTiO}_{3}$ would result in the formation of anion defects for the charge compensation. Justicia and coworkers reported that the anion defects may lead to high visible light absorption ability of the sample [10]. Therefore, the anion defects formed by nitrogen doping seemed to contribute to the formation of the new band gaps of the sample.

Figure 4(b) shows FTIR spectra of $\mathrm{SrTiO}_{3}$ and $\mathrm{N}$-doped $\mathrm{SrTiO}_{3}$ with 4 gram of HMT. Broad absorption in the range of $500-900 \mathrm{~cm}^{-1}$ may be attributed to $\mathrm{TiO}_{6}$ octahedron stretching vibration $[11,12]$, and absorption at 3200-3400 is characteristic of $\mathrm{OH}^{-}$stretching vibration of surface hydroxyl group, and little peak of $1630 \mathrm{~cm}^{-1}$ has been assigned to $\mathrm{H}-\mathrm{O}-\mathrm{H}$ bending vibration of physically adsorbed water $[13,14]$. The vibration of Ti-N could not be observed because of small amount of nitrogen ion which replaced the oxygen ion.

3.5. XPS Analysis. Figure 5 shows the global XPS spectrum and the detailed spectra of three areas in the XPS profile. The shift of binding energy was calibrated using C1s level at $284.6 \mathrm{eV}$ as the internal standard. The energy peaks of Sr, C, $\mathrm{Ti}, \mathrm{O}$, and $\mathrm{N}$ could be observed from the global spectrum. The XPS spectrum for the titanium exhibits two different signals of $\mathrm{Ti} 2 \mathrm{p}_{3 / 2}$ and $\mathrm{Ti} 2 \mathrm{p}_{1 / 2}$ with binding energies at $457.8 \mathrm{eV}$ and $463.3 \mathrm{eV}$, respectively. The peak position of $\mathrm{Ti}$ 


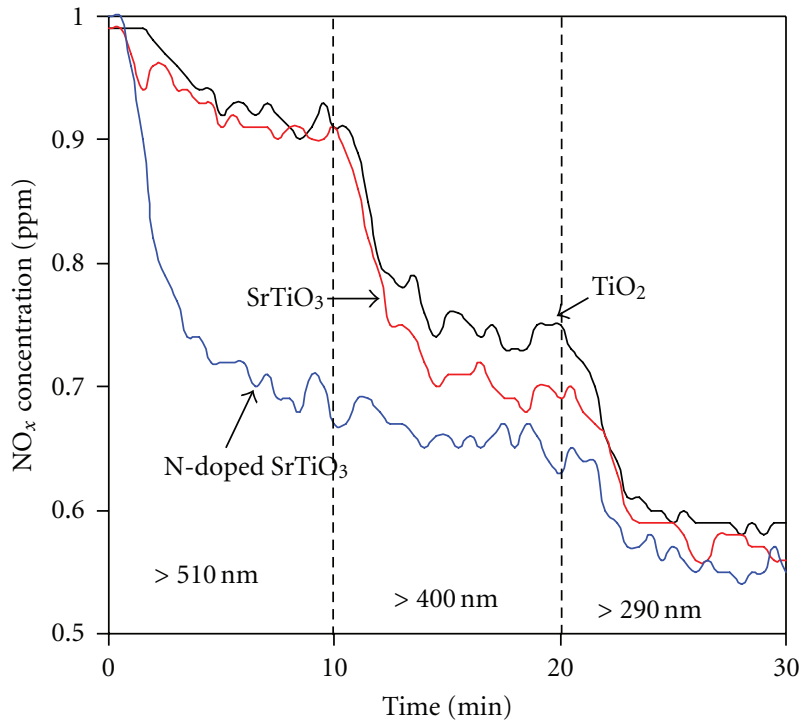

(a)

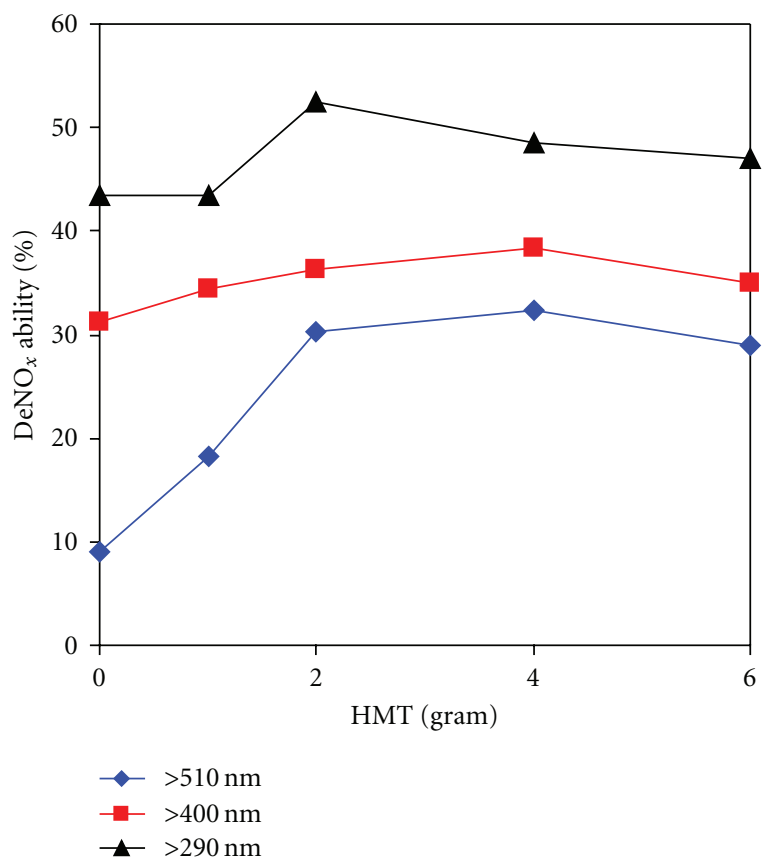

(b)

Figure 6: Photocatalytic activities of $\mathrm{SrTiO}_{3}$ and $\mathrm{N}$-doped $\mathrm{SrTiO}_{3}$ (with 4 gram of HMT) for the oxidative destruction of $\mathrm{NO}_{x}$ under irradiation of various wavelength lights together with those of commercial $\mathrm{TiO}_{2}$ (a); photocatalytic activities of $\mathrm{N}$-doped $\mathrm{SrTiO}_{3}$ prepared with variation of HMT content for the oxidative destruction of $\mathrm{NO}_{x}(\mathrm{~b})$.

$2 \mathrm{p}_{3 / 2}$ corresponds to that of the $\mathrm{Ti}^{4+}$ oxidation state $[15,16]$. The XPS spectra of O1s were observed at $529.1 \mathrm{eV}$ which is the characteristic of metallic oxides [17]. The peak N1s could be observed at $399.2 \mathrm{eV}$ which is assigned as nitrogen physically adsorbed on the surface. After sputtering, small peak at 397.5 could be observed which is assigned as the nitrogen-doped $\mathrm{SrTiO}_{3}[18]$. The amount of nitrogen atomic

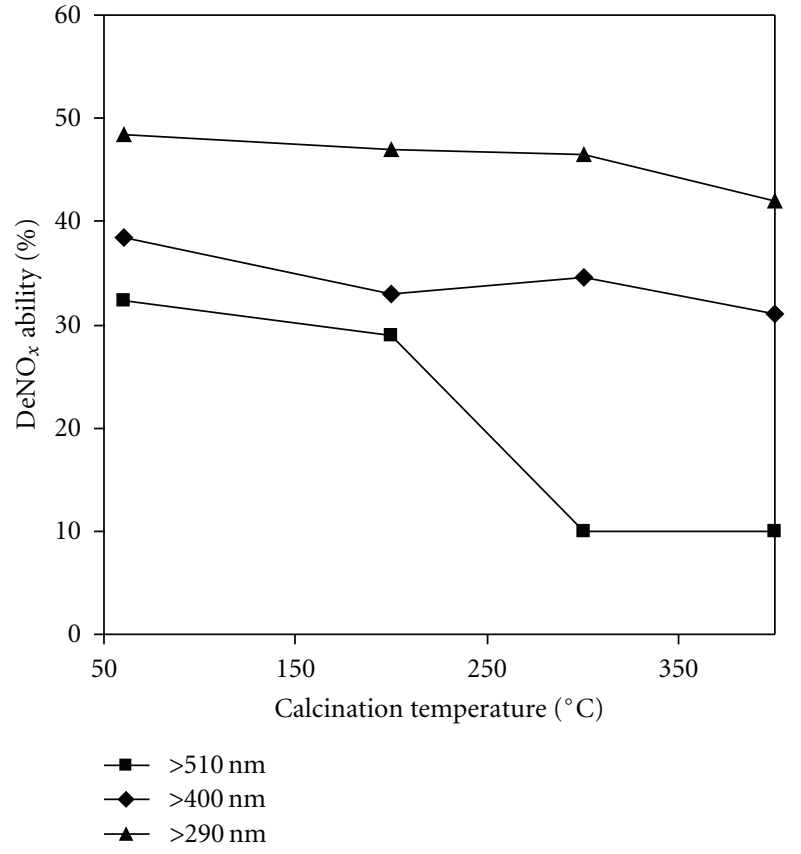

Figure 7: Photocatalytic activities of $\mathrm{N}$-doped $\mathrm{SrTiO}_{3}$ with 4 gram of HMT followed by calcination at various temperatures.

fraction $(\mathrm{N} / \mathrm{Ti})$ after sputtering, 0.032 , was lower than that before sputtering operation (0.064).

3.6. Photocatalytic Activity. Figure 6(a) shows the photocatalytic activities of $\mathrm{SrTiO}_{3}$ and $\mathrm{N}$-doped $\mathrm{SrTiO}_{3}$ for the $\mathrm{NO}_{x}$ elimination under irradiation of visible light $(\lambda>510 \mathrm{~nm})$ $(\lambda>400 \mathrm{~nm})$ and UV light $(\lambda>290 \mathrm{~nm}$ together with those of commercial $\mathrm{TiO}_{2}$ (Degussa P25). The mechanism of photocatalytic activity of $\mathrm{NO}_{x}$ elimination is related to the electron/hole pairs formed by the photoexitation of catalyst. In the presence of oxygen, the electron in the conduction band is trapped by the molecular oxygen to form $\cdot \mathrm{O}_{2}{ }^{-}$, which can generate active $\cdot \mathrm{OOH}$ radicals. The $\mathrm{NO}_{x}$ reacts with $\cdot \mathrm{OOH}, \mathrm{O}_{2}$, and very small amount of $\mathrm{H}_{2} \mathrm{O}$ in the air to produce $\mathrm{HNO}_{2}$ or $\mathrm{HNO}_{3}$ [19-21].

As expected from the large band gap energy, the photocatalytic activities of both $\mathrm{SrTiO}_{3}$ and commercial $\mathrm{TiO}_{2}$ under visible light irradiation $(\lambda>510 \mathrm{~nm})$ were quite low, but $\mathrm{N}$-doped $\mathrm{SrTiO}_{3}$ showed excellent activity. It was also notable that $\mathrm{N}$-doped $\mathrm{SrTiO}_{3}$ showed photocatalytic activity superior to both $\mathrm{SrTiO}_{3}$ and commercial $\mathrm{TiO}_{2}$ even under UV-light irradiation $(\lambda>290 \mathrm{~nm})$, indicating that the visible light responsive photocatalytic activity was induced without loss of the activity under UV-light irradiation by the solvothermal nitrogen doping in $\mathrm{SrTiO}_{3}$.

Figure 6(b) shows the effect of HMT concentration on the photocatalytic abilities. The optimum photocatalytic ability could be achieved at 4 gram of HMT and the addition of excess amount of HMT (up to 6 gram) resulted in decreasing the photocatalytic ability a little. The increase of the photocatalytic activity in the initial stage of nitrogen doping may be due to the positive effect to increase the visible 
light absorption ability, and the decrease of it by the excess amount of HMT addition may be due to the negative effect to increase the amount of lattice defects which act as the recombination center of photoinduced electrons and holes.

Figure 7 shows the effect of temperature on the photocatalytic ability. The photocatalytic ability under UVlight irradiation $(\lambda>290 \mathrm{~nm}$ and $400 \mathrm{~nm})$ did not change so much even after heating at $400^{\circ} \mathrm{C}$. In contrast, the activity under visible light irradiation was almost constant up to $200^{\circ} \mathrm{C}$ but greatly decreased by calcination above $300^{\circ} \mathrm{C}$. It is because of the release of nitrogen ion doped in the lattice at high temperature.

\section{Conclusions}

Perovskite-type N-doped $\mathrm{SrTiO}_{3}$ powder was successfully synthesized by solvothermal method using HMT as nitrogen source. The products consisted of spherical nanoparticles of 50-80 nm in diameter. N-doped $\mathrm{SrTiO}_{3}$ showed excellent photocatalytic activity under both UV and visible light irradiation, that is, the photocatalytic activity of $\mathrm{N}$-doped $\mathrm{SrTiO}_{3}$ for $\mathrm{DeNO}_{x}$ reaction was greater than that of $\mathrm{SrTiO}_{3}$ or $\mathrm{TiO}_{2}$ (Degussa $\mathrm{P}-25$ ) in both visible light region $(>510 \mathrm{~nm})$ and UV light region $(<290 \mathrm{~nm})$. The high visible light photocatalytic activity of this substance is caused by a generation of a new band gap that absorbs visible light.

\section{Acknowledgment}

This research was partially supported by the Ministry of Education, Culture, Sports, Science and Technology, Special Education and Research Expenses on "Post-Silicon Materials and Devices Research Alliance".

\section{References}

[1] H. Zhang, X. Wu, Y. Wang et al., "Preparation of $\mathrm{Fe}_{2} \mathrm{O}_{3} / \mathrm{SrTiO}_{3}$ composite powders and their photocatalytic properties," Journal of Physics and Chemistry of Solids, vol. 68, no. 2, pp. 280283, 2007.

[2] T. Ohno, T. Tsubota, Y. Nakamura, and K. Sayama, "Preparation of $\mathrm{S}, \mathrm{C}$ cation-codoped $\mathrm{SrTiO}_{3}$ and its photocatalytic activity under visible light," Applied Catalysis A: General, vol. 288, no. 1-2, pp. 74-79, 2005.

[3] J. Wang, S. Yin, M. Komatsu, Q. Zhang, F. Saito, and T. Sato, "Preparation and characterization of nitrogen doped $\mathrm{SrTiO}_{3}$ photocatalyst," Journal of Photochemistry and Photobiology A: Chemistry, vol. 165, no. 1-3, pp. 149-156, 2004.

[4] T. Ishii, H. Kato, and A. Kudo, " $\mathrm{H}_{2}$ evolution from an aqueous methanol solution on $\mathrm{SrTiO}_{3}$ photocatalysts codoped with chromium and tantalum ions under visible light irradiation," Journal of Photochemistry and Photobiology A: Chemistry, vol. 163, no. 1-2, pp. 181-186, 2004.

[5] M. Miyauchi, M. Takashio, and H. Tobimatsu, "Photocatalytic activity of $\mathrm{SrTiO}_{3}$ codoped with nitrogen and lanthanum under visible light illumination," Langmuir, vol. 20, no. 1, pp. 232-236, 2004.

[6] J. Wang, H. Li, H. Li, S. Yin, and T. Sato, "Preparation and photocatalytic activity of visible light-active sulfur and nitrogen co-doped $\mathrm{SrTiO}_{3}$," Solid State Sciences, vol. 11, no. 1, pp. 182-188, 2009.

[7] J. Wang, S. Yin, M. Komatsu, Q. Zhang, F. Saito, and T. Sato, "Photo-oxidation properties of nitrogen doped $\mathrm{SrTiO}_{3}$ made by mechanical activation," Applied Catalysis B: Environmental, vol. 52, no. 1, pp. 11-21, 2004.

[8] J.-H. Yan, Y.-R. Zhu, Y.-G. Tang, and S.-Q. Zheng, "Nitrogendoped $\mathrm{SrTiO}_{3} / \mathrm{TiO}_{2}$ composite photocatalysts for hydrogen production under visible light irradiation," Journal of Alloys and Compounds, vol. 472, no. 1-2, pp. 429-433, 2009.

[9] S. Ahuja and T. R. N. Kutty, "Nanoparticles of $\mathrm{SrTiO}_{3}$ prepared by gel to crystallite conversion and their photocatalytic activity in the mineralization of phenol," Journal of Photochemistry and Photobiology A: Chemistry, vol. 97, no. 1-2, pp. 99-107, 1996.

[10] I. Justicia, P. Ordejón, G. Canto et al., "Designed selfdoped titanium oxide thin films for efficient visible-light photocatalysis," Advanced Materials, vol. 14, no. 19, pp. 13991402, 2002.

[11] S. Tan, S. Yue, and Y. Zhang, "Jahn-Teller distortion induced by $\mathrm{Mg} / \mathrm{Zn}$ substitution on $\mathrm{Mn}$ sites in the perovskite manganites," Physics Letters A, vol. 319, no. 5-6, pp. 530-538, 2003.

[12] J. W. Liu, G. Chen, Z. H. Li, and Z. G. Zhang, "Electronic structure and visible light photocatalysis water splitting property of chromium-doped $\mathrm{SrTiO}_{3}$," Journal of Solid State Chemistry, vol. 179, no. 12, pp. 3704-3708, 2006.

[13] K. M. Parida and N. Sahu, "Visible light induced photocatalytic activity of rare earth titania nanocomposites," Journal of Molecular Catalysis A: Chemical, vol. 287, no. 1-2, pp. 151-158, 2008.

[14] J. Geng, D. Yang, J. Zhu, D. Chen, and Z. Jiang, "Nitrogendoped $\mathrm{TiO}_{2}$ nanotubes with enhanced photocatalytic activity synthesized by a facile wet chemistry method," Materials Research Bulletin, vol. 44, no. 1, pp. 146-150, 2009.

[15] S. Martínez-Méndez, Y. Henríquez, O. Domínguez, L. D'Ornelas, and H. Krentzien, "Catalytic properties of silica supported titanium, vanadium and niobium oxide nanoparticles towards the oxidation of saturated and unsaturated hydrocarbons," Journal of Molecular Catalysis A: Chemical, vol. 252, no. 1-2, pp. 226-234, 2006.

[16] R. E. Tanner, Y. Liang, and E. I. Altman, "Structure and chemical reactivity of adsorbed carboxylic acids on anatase $\mathrm{TiO}_{2}$ (001)," Surface Science, vol. 506, no. 3, pp. 251-271, 2002.

[17] M. Z. Atashbar, H. T. Sun, B. Gong, W. Wlodarski, and R. Lamb, "XPS study of Nb-doped oxygen sensing $\mathrm{TiO}_{2}$ thin films prepared by sol-gel method," Thin Solid Films, vol. 326, no. 1-2, pp. 238-244, 1998.

[18] J. Wang, S. Yin, M. Komatsu, and T. Sato, "Lanthanum and nitrogen co-doped $\mathrm{SrTiO}_{3}$ powders as visible light sensitive photocatalyst," Journal of the European Ceramic Society, vol. 25, no. 13, pp. 3207-3212, 2005.

[19] S. Yin and T. Sato, "Synthesis and photocatalytic properties of fibrous titania prepared from protonic layered tetratitanate precursor in supercritical alcohols," Industrial and Engineering Chemistry Research, vol. 39, no. 12, pp. 4526-4530, 2000.

[20] H. Gerischer and A. Heller, "The role of oxygen in photooxidation of organic molecules on semiconductor particles," Journal of Physical Chemistry, vol. 95, no. 13, pp. 5261-5267, 1991.

[21] S. Yin, Y. Aita, M. Komatsu, J. Wang, Q. Tang, and T. Sato, "Synthesis of excellent visible-light responsive $\mathrm{TiO}_{2-\mathrm{x}} \mathrm{N}_{y}$ photocatalyst by a homogeneous precipitation- solvothermal process," Journal of Materials Chemistry, vol. 15, no. 6, pp. 674-682, 2005. 

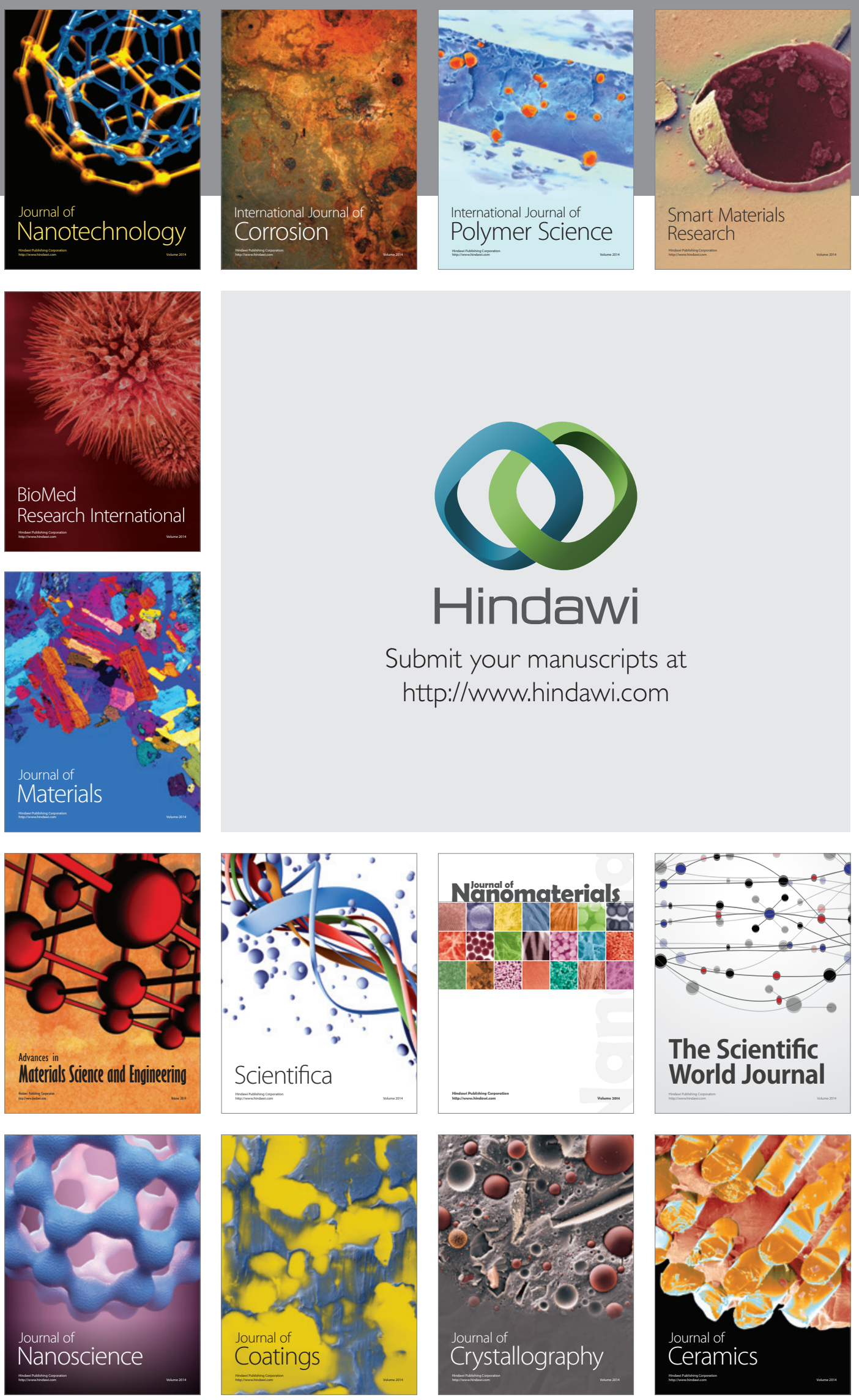

The Scientific World Journal

Submit your manuscripts at

http://www.hindawi.com

\section{World Journal}

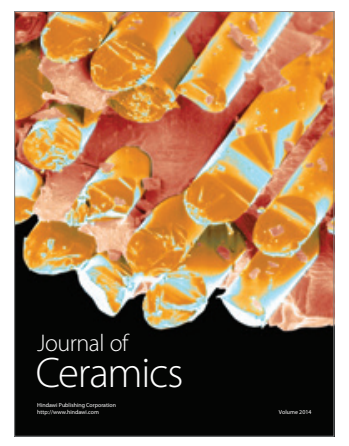

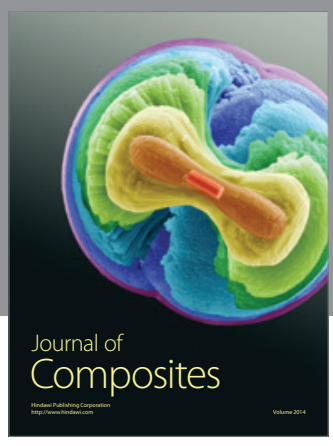
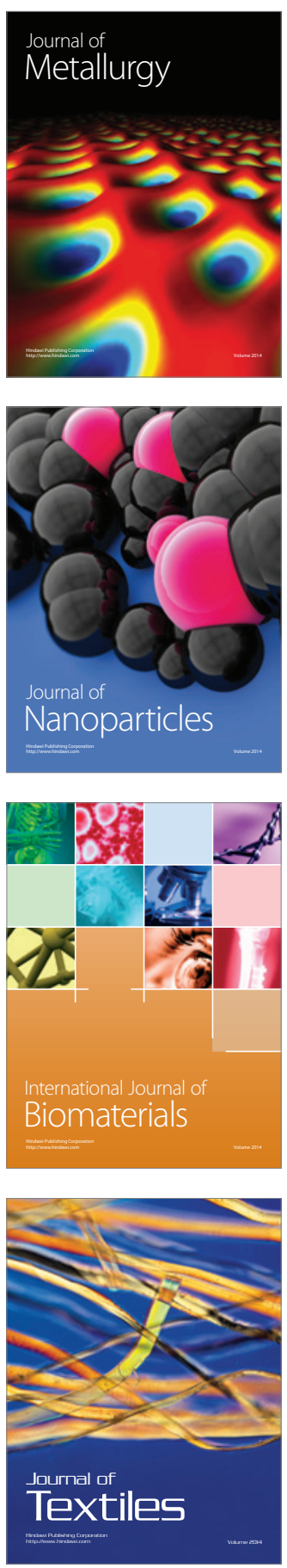